\title{
Application of genetic algorithm and analytic hierarchy process to generate an oil spill risk map
}

\begin{abstract}
Extracting and transporting a significant amount of oil and gas from the Persian Gulf have brought devastating damages to marine environment due to oil spills and water pollution. The oil spill in water brings damages to the ecosystem, coastline businesses and human health; particularly to fishery and tourism activities. Hence, it is a crucial task to model oil spill damages and evaluate risks. By identifying the oil slick behaviour and considering the velocity and cleaning capacity of oil cleaning vessels, the genetic algorithm (GA) was used to obtain the optimum placement of the vessels for several oil spill scenarios. Meanwhile, six major risks of damages were identified for the Persian Gulf in terms of marine ecosystem, tourism, fisheries, beach entry bans, commercial and transit ports closures. All these factors were systematically analyzed using analytic hierarchy process (AHP). AHP provided a quantitative analysis of probabilities of hazards, financial losses and environmental damages. Based on location, volume of oil spill, weather condition and optimum placement of oil cleaning vessels, the risk map of oil spill in the Persian Gulf was developed and the effects of each major risk and overall risks were assessed.
\end{abstract}

Keywords: Genetic algorithm, Analytic hierarchy process, Oil spill risk map, Persian Gulf
Volume 6 Issue I - 2017

\author{
MA Badri,' A Sedaghat ${ }^{2}$ \\ 'Research Institute for Subsea Science \& Technology, Isfahan \\ University of Technology, Iran \\ ${ }^{2}$ Department of Mechanical Engineering, Isfahan University of \\ Technology, Iran
}

\begin{abstract}
Correspondence: MA Badri, Research Institute for Subsea Science \& Technology, Isfahan University of Technology, Iran,
\end{abstract} Emailmalbdr@cc.iut.ac.ir

Received: July 08, 2017| Published: July 25, 2017

\section{Introduction}

The oil spill damages include undesirable effects on ecosystem, adverse effects on coastline economy and risks on human health. ${ }^{1}$ Therefore, it is essential to perform a risk analysis to determine the level of damages and to identify the location and type of major risks. Venkatesh ${ }^{2}$ has introduced an oil spill behaviour model of the Canadian atmospheric environment. Venkatesh ${ }^{3}$ also employed a numerical simulation of movement of 1991 oil spills in the Persian Gulf. Yanagi ${ }^{4}$ introduced clockwise phase propagation of semi-diurnal tides in the Gulf of Thailand and used it in oil slick behaviour. Wojtaszek- ${ }^{5}$ studied the application of a transport model for building contingency maps of oil spills in the North Sea and Wang ${ }^{6}$ developed a two-dimensional numerical simulation for transport and the fate of oil spills.

To manage an oil spill, it is crucial to minimize the probability of occurrence of an oil spill event, ${ }^{7}$ optimize the risk response process, and the best location of cleaning vessels once the event occurs. The risk identification processes were studied by Kassomenos \& Saaty ${ }^{8,9}$ and facilitated by the event-tree technique within AHP methodology. This process has offered a rational framework for solving multicriteria decision-making problems. The outcome of its application has been a prioritization of the alternative choices by means of numerical factors. Montazerolghaem et al. ${ }^{10}$ have used the genetic algorithm to optimize the placement of 10 oil cleaning vessels in operation in some ports of the Persian Gulf. Several oil spill scenarios in the Western and Eastern regions of the Persian Gulf were studied and a methodology was developed for the performance of oil spill risk analysis in this region. This methodology considered the processes of probability and consequence assessment based on AHP method.

The purpose of this study is to determine the optimal position vector of oil cleaning vessels in the Persian Gulf in order to minimize the oil spill damages. For the oil fields in the Persian Gulf and oil cleaning vessels in Kharg and Asaluye ports, several scenarios are investigated for oil spill events in the Persian Gulf. To assess these scenarios, first, the oil slick behaviour is identified and evaluated; then, the Genetic Algorithm (GA) is used to determine the optimum number of vessels for minimum arrival time based on velocity and cleaning capacity of each vessel. The aim of this study is to minimize the oil spill damage by cleaning the polluted area at the shortest possible time. Therefore, a number of 10 vessels are adopted for cleaning up operations in the Persian Gulf. Then, the optimal position of vessels applied to all oil spill scenarios to obtain for Western and Eastern regions of the Persian Gulf using GA. This research is devoted to the assessment of risks occurring after an oil spill event and the risk response process. The main objective is elaboration of the basic processes of a risk analysis, including identification of risks, assessment of their probability and finally, actual risk assessment. The analysis is performed in a coastal area located in the Persian Gulf, allowing the demonstration of some oil spill scenarios. Some features such as existence of wetlands, fisheries and a port with both commercial and passengers' services are considered.

In this paper, six major risks of damages to economy and ecosystem of the Persian Gulf are introduced (L1 to L6 in section 2.3). They are specified as the marine ecosystem, tourism, fisheries, beach entry bans to public, commercial and transit ports closures, and coastline ecosystem. AHP is used to provide a quantitative analysis of probabilities of hazards, financial losses and environmental damages. Based on location, volume of oil spill and weather condition, the risk map of the Persian Gulf is presented and explained for each major risk using the optimum placement of oil cleaning vessels. In order to be able to include a function for the optimization procedure by GA, oil spill modelling is completed considering a probability wind field. Genetic Algorithm is used to determine the optimum position of oil cleaning vessels by considering velocity and cleaning capacity of vessels for different scenarios. In this paper, section 2 gives a brief account on methodology. An elaborated flow model which has been calibrated as well in the authors' previous researches is invoked in this study. ${ }^{11}$ Finally, results and conclusion are presented in sections 
3 and 4 respectively. The study moves towards the development of a quantitative methodology for oil spill risk analysis with real probabilities of hazards for the Persian Gulf as a real sample.

\section{Methodology}

\section{Optimization method and objective function}

Economic and ecological damages due to the release of oil in the marine environment are functions of exposed time and oil type. Thus, the amount of economic and ecological damages is a function of time and volume of oil released at the marine environment. The oil pollution damage can be directly related to oil falling time and slick. Obviously, the larger area covered by the oil spill may cause more damages to the environment. The damage may be minimal when the oil slick can be cleaned in the shortest possible time. By defining $n$ and $m$ as the number of vessels and ports, the position vector is given by vo $\{1,2, \ldots \mathrm{m}\}^{\mathrm{n}}$, where $v(i)$ is the port in which the vessel $i$ is located. Hence, each out looking solution is a string of integers from the set $\{1,2, \ldots \mathrm{m}\}$. Each out looking solution is composed of $\mathrm{n}$ genes, with each gene representing a vessel and taking values from $\{1,2, \ldots \mathrm{m}\}$. The goal is to find the position vector to minimize the oil spill damages which mathematically means, $\operatorname{Min} \sum_{c=1}^{N} P_{C} D(\mathrm{c}, \mathrm{v})$. Where $P_{C}$ is the probability of oil spill in location (cell) $c, \mathrm{~N}$ is the number of cells and $\mathrm{D}(\mathrm{c}, \mathrm{v})$ is the damage quantity in the cell $c$ if the vector location is $v^{1}$ In order to determine the damage function $\mathrm{D}(\mathrm{c}, \mathrm{v})$, the cell incident $c$ and the position vector $v$ have to be identified. The damage function $\mathrm{D}(\mathrm{c}, \mathrm{v})$ should possess a minimum for a certain arrangement of vessels. Here, for a system with $\mathrm{n}$ vessels, given a location vector, the number of cases that have to be analyzed for each incident cell is calculated from $\left(\frac{n}{1}\right)+\left(\frac{n}{2}\right)+\ldots+\left(\frac{n}{n}\right)=2^{n}-1$

\section{Obtaining the damage function}

The damage of oil pollution depends on time and volume of oil spillage. When the residence time of oil in water is greater, the damage will be higher. The way in which the damage is related to the time and the volume of pollutant is via area of the oil spill. A larger area of oil spill produces more damage to marine ecosystem, particularly to bird and fish lives.

The formula which relates the damage and the area of the oil spill is given $D(t)=\int_{0}^{t} A(\tau) \mathrm{d} \tau$

Where $\mathrm{D}(\mathrm{t})$ is damage until the time $\mathrm{t}$ and is the area of oil spill at time $\mathrm{A}(\tau)$. The next step is to consider a model for area of the oil spill. Mackay's model is a popular model which has been widely adopted. For this case study, the Mackay model is considered by a differential equation based on the change of oil spill area over the time in shallow water. Since the Persian Gulf is also a shallow water, this model can be suited for this region. Mackay's model is expressed by $\frac{d A}{d t}=K V^{\frac{4}{3}} \cdot \frac{1}{A}$ where $\mathrm{A}$ is the area of oil pollutant $\left(\mathrm{m}^{2}\right), \mathrm{V}$ is the volume of oil spill $\left(\mathrm{m}^{3}\right)$ and $\mathrm{K}$ is a constant $(150 \mathrm{sec}-1) .{ }^{1}$ Based on several case studies of short term numerical modelling of oil spill, the volume change of oil spill was derived as $V=V_{0} \exp (-\lambda t) \quad{ }_{11,12} \lambda$ is a dimensionless constant (0.11) and V0 is the initial volume of oil spill in $\mathrm{m} 3$. The pollution area is determined as a function of time by integrating Mackay's model and aided by the assumption of

$\lim _{t \rightarrow 0} A(\mathrm{t})=0$
Each vessel is specified by two characteristic variables of velocity and cleaning capacity. vess $(i, 1)$ is the speed of vessel and vess $(i, 2)$ is the cleaning capacity of vessel $\mathrm{i}$. Also, the matrix of distances between cells and ports is denoted by dist; so dist is a matrix with $\mathrm{N}$ rows and $\mathrm{m}$ columns and $\operatorname{dist}(c, k)$ is the distance between cell $\mathrm{c}$ and port $\mathrm{k}$. Therefore, if the first vessel by cleaning capacity of $Q v i$ arrives in the polluted area at time ti, the area of the oil spill is calculated. ${ }^{10}$ Moreover, it is assumed that the area of the oil spill increases only until the arrival time of the cleaning vessel; then the area is reduced by a linear function of time. Thus, if all vessels are assumed in cleaning operation, the area equation of the oil spill may be given by

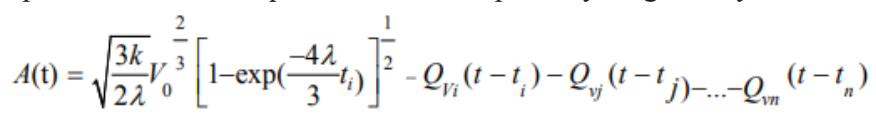

The stop time of cleaning operating is determined by employing the $\mathrm{A}$ (tstop) $=0$. So the stop time (tstop) is determined. ${ }^{10}$ The damage of the oil spill at the end of cleaning operation is calculated by integrating area until it approaches the stop time.

\section{Risk Analysis for the Persian Gulf}

Most classical optimization methods generate a deterministic sequence of computation based on gradient or higher-order derivatives of an objective function. Genetic Algorithms perform a multiple directional search by maintaining a population of potential solutions. Therefore, in present study, the Genetic Algorithm is adopted. A number of short-term risks are initially recorded to present in an event-tree, accounting the assumed characteristics of the Persian Gulf. The identified risks were classified in some categories based on their hierarchy position in the event-tree. They are defined as direct risks (R1 to R6) and indirect risks. As shown in Table 1, the direct risks are those related to oil spill events directly; however, indirect risks are resulted from the consequence of a direct risk. Since records of oil spill damages are not usually available; therefore, the probability of occurrence of the identified risks is assessed qualitatively. The product of this process is qualitative probability values for every identified risk using a probability scale. The scale proposed contained five probability classes, characterized with the integer numbers from 1 to 5 corresponded to a probability range (Table 2 ). The main parameters affecting the probability of direct risks were $\mathrm{P} 1$ as Oil spill size, P2 as Weather conditions (Weibull distribution) and P3 as Oil spill location. The combination of certain values of 3 parameters is determined certain oil spill scenarios to assess the risk probability.

Table I Direct and indirect risks of oil spill in the Persian Gulf

\begin{tabular}{ll}
\hline RI & Damage to ecosystem \\
R2 & Ban on tourism \& swimming \\
R3 & Ban on fishery \\
R4 & Closure of entry ports \\
R5 & Closure of transit ports \\
R6 & Damage to coastline \\
\hline
\end{tabular}

Table 2 Probability scale

\begin{tabular}{ll}
\hline Description & Probability range \\
\hline very low & $0.0-0.2$ \\
low & $0.2-0.4$ \\
medium & $0.4-0.6$ \\
high & $0.6-0.8$ \\
very high & $0.8-1.0$ \\
\hline
\end{tabular}

The oil spill size is determined in accordance with oil spill categories (Table 3) originated from author's case studies (S1 to S3). The weather conditions are determined by a combination of wind 
speed and direction (W1 to W8). The wind direction is favourable if it resulted in decreasing a certain risk probability and unfavourable if it resulted in increasing a certain risk probability. Based on the above values, 168 different oil spill scenarios may be considered. The probability assessment of direct risks in each of these scenarios is applied by AHP. Definition of the problem parameters and their possible values are introduced namely P1, P2 and P3 with values of S1-S3, W1-W8 and L1-L6 respectively (Table 3). Comparisons of the problem parameters in pairs are directly according to the experience of the authors. When the importance of parameter $\mathrm{j}$ is higher than the inverse values of the comparison, scale is used. The matrices of parameters $\mathrm{P} 2$ and $\mathrm{P} 3$ are similar. The additional parameters such as Oil type and Season are left for future researches.

Table 3 Parameter values

\begin{tabular}{llll}
\hline P3 & $\begin{array}{l}\text { P2 (Wind velocity) } \\
\text { [m/sec] }\end{array}$ & $\begin{array}{l}\text { Wind } \\
\text { Prob. (\%) }\end{array}$ & PI [tone] \\
\hline LI: close to wetlands & WI:0-4, favourable & 30 & SI: < I0 \\
L2: close to tourism & W2: 5-9, favourable & 52 & S2:10-500 \\
$\begin{array}{l}\text { installations } \\
\text { L3: close to fisheries }\end{array}$ & W3: I0-14, favourable & 16 & S3: $>500$ \\
L4: port entrance & W4: $>14$, favourable & 2 & \\
L5: commercial quay & W5 -W8, unfavourable & $\begin{array}{l}\text { The same } \\
\text { asWI -W4 }\end{array}$ & \\
L6: passengers' quay & & &
\end{tabular}

\section{Results and discussion}

Table 4 summarizes characteristics of 10 oil cleaning vessels in operation within the Persian Gulf. Figure 1 shows convergence of the Genetic Algorithms due to the expected damage for a typical case study with 10 vessels. ${ }^{13,10}$

Table 4 Characteristics of oil cleaning vessels

\begin{tabular}{lll}
\hline $\begin{array}{l}\text { Cleaning capacity } \\
\left(\mathbf{k m}^{2} / \text { hour }\right)\end{array}$ & $\begin{array}{l}\text { Velocity } \\
(\mathbf{k m} / \text { hour) }\end{array}$ & Vessel's Number \\
\hline 0.12 & 14 & $1,3,5,6,7 \& 8$ \\
0.06 & 12 & $2 \& 9$ \\
0.12 & 13 & $4 \& 10$
\end{tabular}

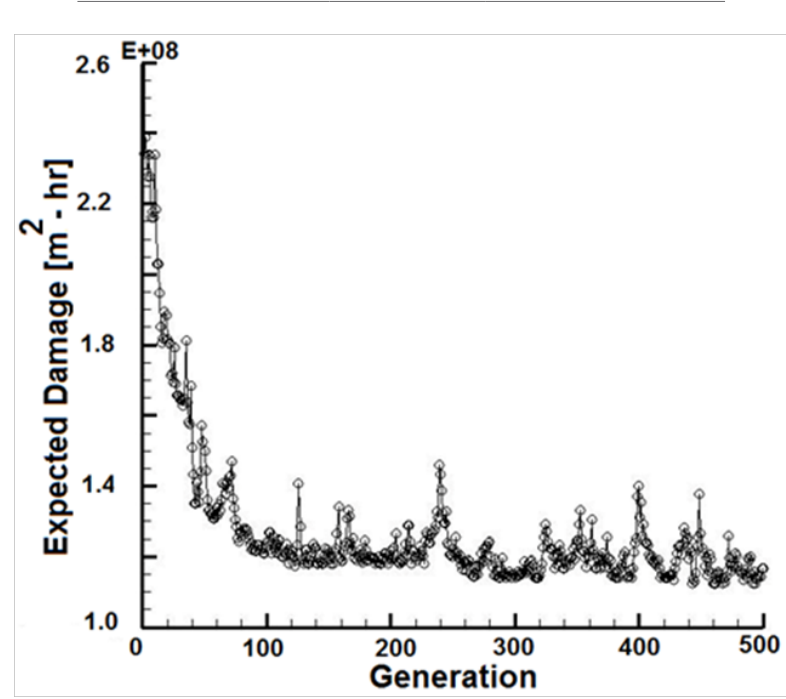

Figure I A typical result for convergence of the Genetic Algorithms.

The dynamical field was previously obtained using Kelvin wave expansion. ${ }^{11}$ The actual data for Habash oil spill event and computed results based on GULFSLIK model ${ }^{14}$ were observed to be in a fairly good agreement. This was invoked in order to formulate oil slick surface area to provide an optimization problem. Figure 2 shows the optimum position of oil cleaning vessels in this case study in the form

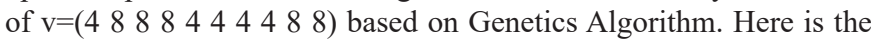
port in which the vessel i may be located. Thus the optimum location for the vessels $1,5,6,7,8$ is the port 4, i.e. Kharg Island, and for the vessels $2,3,4,9,10$ is the port 8 , i.e. Asaluye port. It should be noted that the vessels 2, 9, 10 have lower speeds and cleaning capacities compared with other vessels.

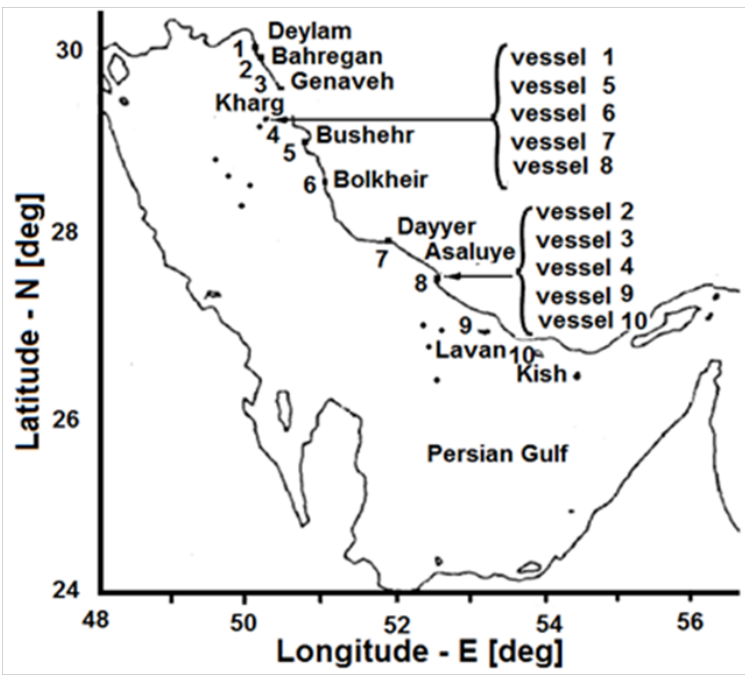

Figure 2 Optimum position of cleaning vessels.

The methodology developed for the performance of oil spill risk analysis in the Persian Gulf is concerned with the processes of probability and consequence assessment with a risk prioritization based on AHP. Based on optimum arrangements of the oil cleaning vessels discussed, the effects of this arrangement on the major risks are shown in Figure 3. As it can be seen in Figure 3a, the north-west of Persian Gulf may be in high risk zone of ecosystem due to the protected national parks of Khargo and Farsi Island with a variety of natural ecosystems. Figure $3 \mathrm{~b}$ depicts the high tourism bans occurrence in the north-west of the Persian Gulf on the beaches of Bushehr, Genaveh, and Dylam and also, in the south east of the Persian Gulf near the beaches of Omoghiran of Dubai. Figure 3c represents high risk zones for fishing near Abumosa and Lavan in east and Dylam in the north west of the Persian Gulf, where centres of fishery and pearl businesses are located. Figure $3 \mathrm{~d}$ shows that the port closure risks due to oil spill are higher in the west of the Persian Gulf near Daylam, Bahregan, and Genaveh ports and also in the south west of the Persian Gulf and Saudi Arabia. Figure $3 e$ indicates the high risk zones for trade and transit ports which are mainly located near the north west of the Persian Gulf and the major oil terminals of Khark and Surena and also, Siri and Salman oil terminals. Figure $3 \mathrm{f}$ presents damages to coastlines in case of the oil spill. The high risk zones are Khark coastlines near the beaches of Siri Island such as Alvand, Esfand, Dena, and Sivand.

In Figure 4, a final arrangement for all vessels is proposed as well and an overall risk map is provided for the Persian Gulf. According to the calculations, the most risky scenario in the risk map is a refined oil with a spill size greater than 500 tones, unfavourable weather condition with wind speed greater than $14[\mathrm{~m} / \mathrm{sec}]$, and is located in passengers quay and happens in spring. The high risk zones are related to the north west of the Persian Gulf near the islands of Khark, Daylam, and Bahregan and also, in the east of the Persian Gulf near the islands of Siri, Kish, and Lavan. ${ }^{15-17}$ 


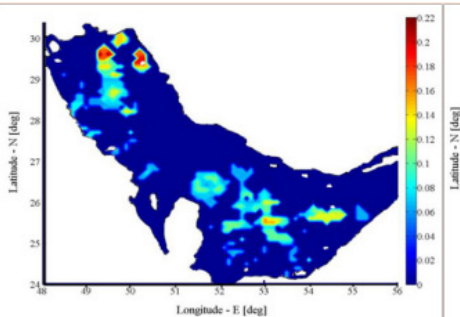

(a) The ecosystem risk (R1)

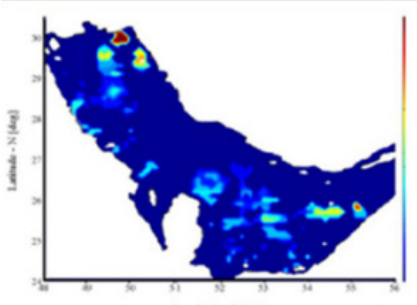

(c) The fishery ban riak (R3)

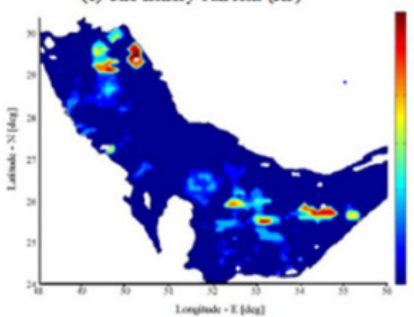

(e) The trade and transit port closure risk (R3)

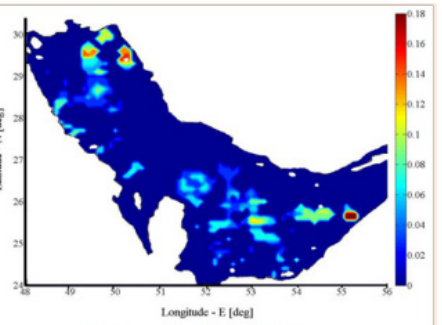

(b) The tourism ban risk (R2)

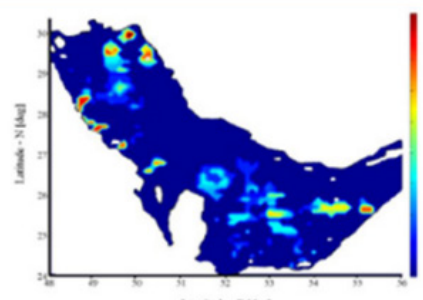

(d) The entry port closure risk (R4)

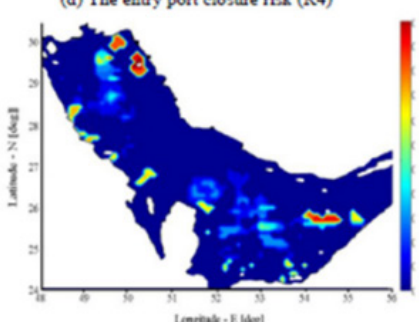

(f) The coastline ecosystem damage risk (R3)
Figure 3 Risk Map for the Persian Gulf based on the major risks factors.

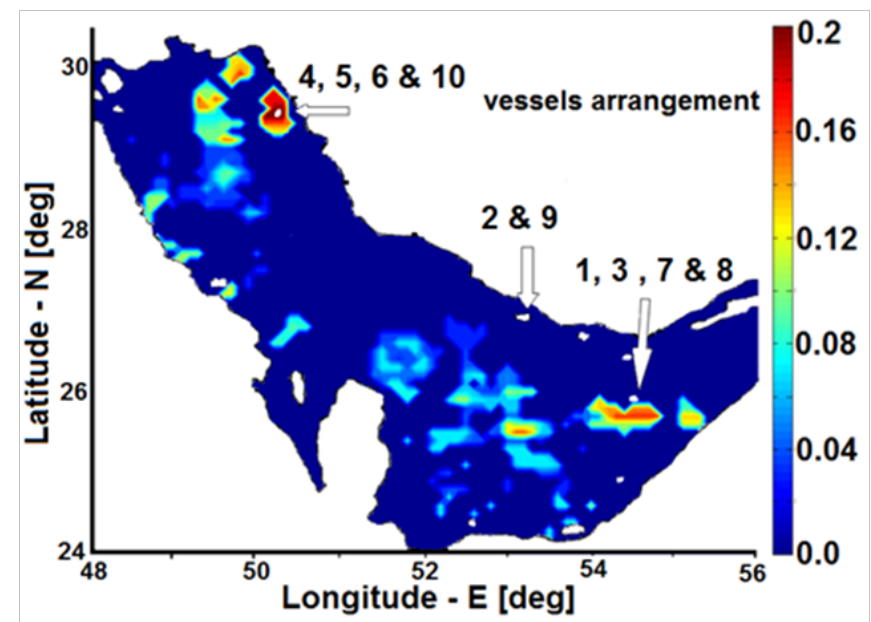

Figure 4 Overall Risk Map for the Persian Gulf with a proposed vessels arrangement.

\section{Conclusion}

Some case studies were undertaken to prepare scenarios for oil cleaning processes in the Persian Gulf upon most probable hazards. Genetic Algorithm (GA) was used to determine the optimal position of 10 oil cleaning vessels by considering velocity and cleaning capacity of each vessel for different scenarios of oil spill. A methodology was developed for performance enhancement of oil spill risk analysis based on Analytic Hierarchy Process (AHP). In the related event-tree, some risks such as degradation of coastal eco-system, port entrance blockage, accident fire/explosion, ban on swimming and fishing activities were considered. The model employed an approximate flow model, an analytical wind field using Weibull probability distribution and an oil slick surface area used in GA for the optimization problem. Hence, the capability of using an analytical wind field time series and GA simultaneously led to optimizing the location of the cleaning vessels, preparing a qualitative risk prioritization based on AHP and developing a qualitative risk map for the Persian Gulf.

\section{Acknowledgments}

None.

\section{Conflicts of interest}

None.

\section{References}

1. Mackay D. A Mathematical Model of Oil Spill Behaviour. Environmental Protection Service, Fisheries and Environmental, Canada. 1980.

2. Venkatesh S. The Oil Spill Behaviour Model of the Canadian Atmospheric Environment Service, Part I: Theory and model evaluation. Atmosphere-Ocean. 1988;26(1):93-108.

3. Venkatesh S, TS Murty. Numerical Simulation of the Movement of the 1991 Oil Spills in the Arabian Gulf. Water, Air and Soil Pollution. 1994;74(3-4):211-234.

4. Yanagim T, Takao T. Clockwise Phase Propagation of Semi-Diurnal Tides in the Gulf of Thailand. J of Oceanography. 1998;54(2):143-150.

5. Wojtaszek K. Application of Transport Model for Building Contingency Maps of Oil Spills on the North Sea, Master thesis, TUDELFT. 2003;

6. Wang SD et al. Two-Dimensional Numerical Simulation for Transport and Fate of Oil Spills in Seas. Ocean Engineering. 2005;32(2005):15561571.

7. Al-Rabeh AH, Cekirge HM, Gunay N. A Stochastic Simulation Model of Oil Spill Fate and Transport. Applied Mathematics Modelling. 1989;13(6):322-329.

8. Kassomenos PA. Risk Analysis for Environmental Hazards: the Case of Oil Spills in Crete. Global Nest: Int. J. 2004;6(1):39-51.

9. Saaty TL. How to Make a Decision: The Analytic Hierarchy Process. European J. of Operational Research. 1990;48.

10. Montazerolghaem H. Minimizing the oil spill damage using optimum arrangement of oil cleaning vessels in the Kharg Island and Asaluye SBM. The $10^{\text {th }}$ International Conference on Coasts, Ports and Marine Structures (ICOPMAS2012) Tehran, Iran. 2012.

11. Badri MA, Wilders P. Flow Estimation for the Persian Gulf Using a Kelvin Wave Expansion. Indian J. of Marine Sciences. 2012;41(3):249258.

12. Badri MA, Azimian AR. An Oil Spill Model Based on the Kelvin Wave Theory and Artificial Wind Field for the Persian Gulf. Indian J. of Marine Sciences. 2010;39(2):165-181.

13. Kumar $\mathrm{M}$ et al. Genetic Algorithm: Review and Application. International J. of Information Technology and Knowledge Management. 2010;2:451-454.

14. El-Sabh MI, Murty TS. Simulation of the Movement and Dispersion of Oil Slicks in the Arabian Gulf. Natural Hazards. 1988;1(2):197-219.

15. Admiralty Tide Tables. Admiralty Charts and Publications, Vol. 3, NP. 1999;203-299.

16. Elhakeem AA, Elshorbagy W, Chebbi R et al. Oil Spill Simulation and Validation in the Arabian (Persian) Gulf With Special Reference to the UAE Coast, Water Air Soil Pollution. 2007;184(1-4):243-254.

17. Ommundsen A. Models of Cross Shelf Transport Introduced by the Lofoten Maelstrom. Continental Shelf Research. 2002;22(2002):93113. 